\title{
A New Approach Is Needed to Analyze the Upper Esophageal Sphincter Because Currently Incorporated High-resolution Manometry Analysis Software Package Is Not Perfect
}

TO THE EDITOR: I read with interest the review article by Wang et $\mathrm{al}^{1}$ regarding "High-resolution manometry (HRM) analysis of upper esophageal sphincter (UES) not addressed by the 'Chicago classification'" disorders of the UES may include pharyngeal dysphagia and other cervical symptoms such as globus. Currently automated analysis of HRM provides the details of information such as mean basal UES pressure, mean residual UES pressure, UES relaxation time-to-nadir, UES relaxation duration, UES recovery time, and peak pharyngeal pressure. We have been evaluating whether HRM plays some roles in the assessment of the disorders of the UES with special interest for 4 years. ${ }^{2-4}$

To our experience, the information obtained by the software analysis often is not perfect as well as occasionally being wrong. Figure $1 \mathrm{~A}$ shows erroneous locations of pharyngeal/UES wave markers, which are occurring despite of adequate setting thermal compensation and adjusting the spatial markers. Therefore it should be noted that it is very important to adjust the locations of the pharyngeal/UES wave markers correctly before the assessment of oropharyngeal dysphagia or globus. This problem frequently occurs in the setting of incomplete UES relaxation (Fig. $1 \mathrm{~B})$ and then gives misinformation regarding the duration of UES relaxation. However, it is very hard to correctly adjust UES wave markers under these circumstances. Given that, another new approach for quantitative assessment of UES relaxation should be considered. When we evaluate esophagogastric junction (EGJ) relaxation in the HRM examination, 4-second integrated relaxation pressure (IRP) is one of the best measures of EGJ relaxation, compared to nadir pressure and 3-second IRP. ${ }^{5}$ The opening time of UES is a lot shorter than that of EGJ. This suggests that IRP concept may be inappropriate in the assessment of UES relaxation. In HRM analysis, isobaric contours of 20 $\mathrm{mmHg}$ and $30 \mathrm{mmHg}$ are currently used to assess distal contractile integral and distal segment contraction, respectively. ${ }^{5}$ These isobaric contours might be helpful for a more robust localization of these wave markers and then provide additional new concept regarding a measure of UES relaxation. To our experience, duration of UES relaxation on automated analysis seems to correlate well with the shortest horizontal distance from ending

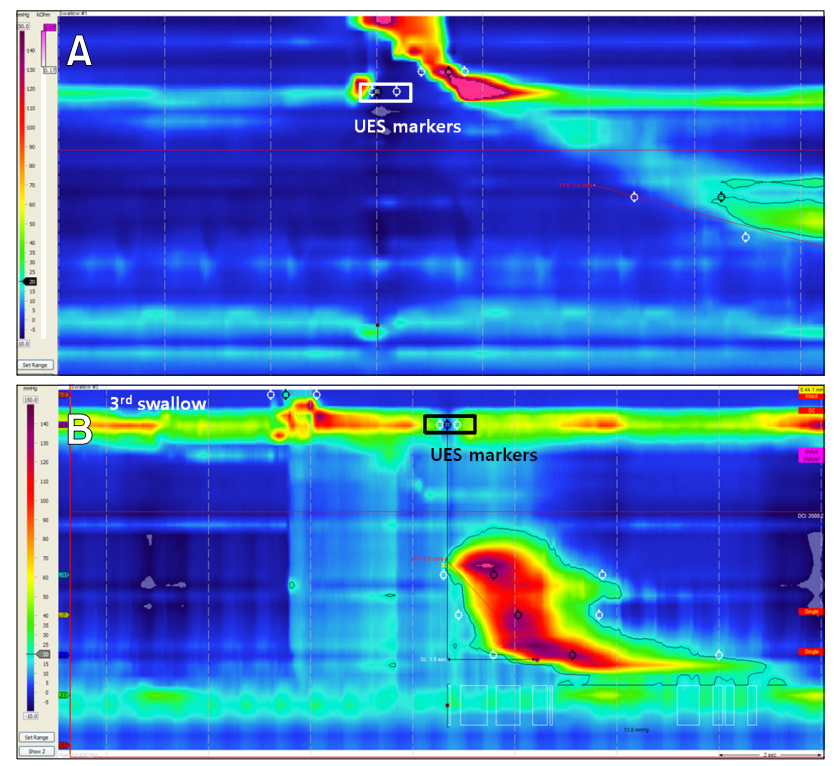

Figure 1. Wrong location of pharyngeal/upper esophageal sphincter wave markers is noted. (A) Starting and ending points of UES relaxation wave makers are improperly located. (B) Starting, center and ending points of UES relaxation wave markers in third swallow are located in belching portion next to the swallow. 

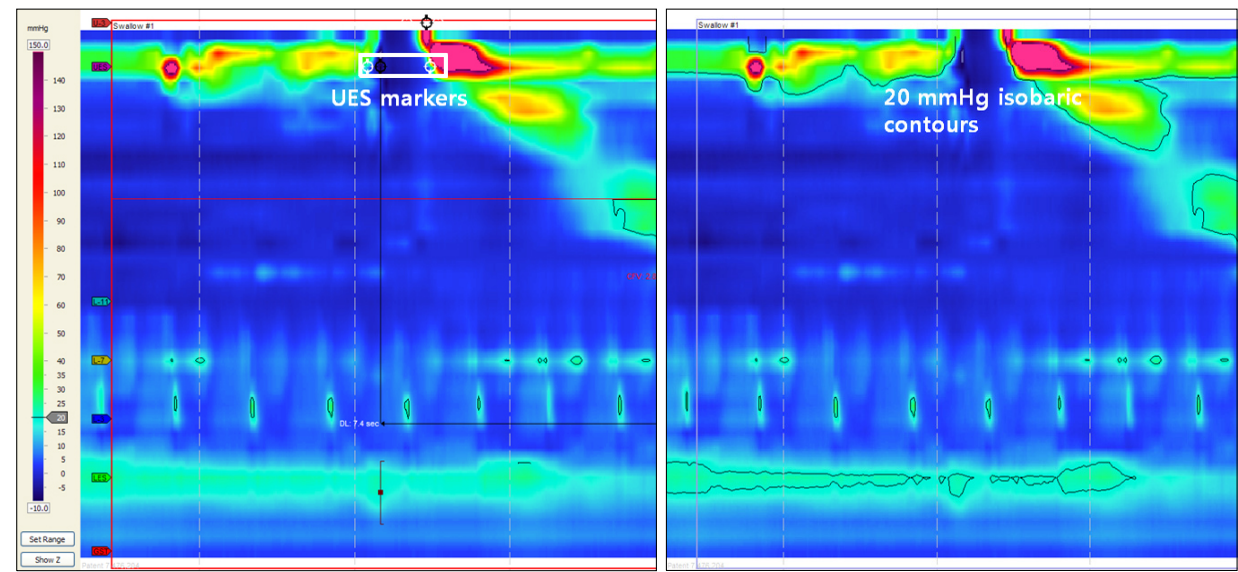

Figure 2. Comparison of duration of the upper esophageal sphincter relaxation between automated analysis and new approach (using $20 \mathrm{mmHg}$ isobaric contours). contour of pre-swallow UES peak to starting contour of post-swallow UES peak with $20 \mathrm{mmHg}$ isobaric contour applied in this analysis (Fig. 2). This issue, however, should be further validated by larger study. In conclusion, we believe that the new approach should be introduced for better evaluation of disorders of the UES.

\section{Tae Hee Lee, ${ }^{1}$ Su Jin Hong ${ }^{2}$ and Joon Seong Lee ${ }^{1}$ \\ ${ }^{1}$ Institute for Digestive Research, Digestive Disease Center Soonchunhyang University Seoul Hospital, Seoul, Korea; and ${ }^{2}$ Department of Internal Medicine, Soonchunhyang University College of Medicine, Bucheon, Gyeonggi-do, Korea}

1. Wang YT, Yazaki E, Sifrim D. High-resolution manometry: esophageal disorders not addressed by the "Chicago classification". J Neurogastroenterol Motil 2012;18:365-372.
2. Lee TH, Lee JS. High-resolution manometry for oropharyngeal dysphagia in a patient with large cervical osteophytes. J Neurogastroenterol Motil 2012;18:338-339.

3. Lee TH, Lee JS, Kim WJ. High resolution impedance manometric findings in dysphagia of Huntington's disease. World J Gastroenterol 2012;18:1695-1699.

4. Lee TH, Lee JS, Park JW, et al. High-resolution impedance manometry facilitates assessment of pharyngeal residue and oropharyngeal dysphagic mechanisms. Dis Esophagus Published Online First: 15 Jul 2013. doi: 10.1111/dote.12101

5. Pandolfino JE, Fox MR, Bredenoord AJ, Kahrilas PJ. High-resolution manometry in clinical practice: utilizing pressure topography to classify oesophageal motility abnormalities. Neurogastroenterol Motil 2009;21:796-806.

\section{Conflicts of interest: None.}

